There is no third face of agreement

Author(s): Alex Alsina and Boban Arsenijević

Source: Language, Vol. 88, No. 2 (JUNE 2012), pp. 388-389

Published by: Linguistic Society of America

Stable URL: https://www.jstor.org/stable/23251837

Accessed: 03-08-2018 07:46 UTC

\title{
REFERENCES
}

Linked references are available on JSTOR for this article:

https://www.jstor.org/stable/23251837?seq=1\&cid=pdf-reference\#references_tab_contents You may need to $\log$ in to JSTOR to access the linked references.

JSTOR is a not-for-profit service that helps scholars, researchers, and students discover, use, and build upon a wide range of content in a trusted digital archive. We use information technology and tools to increase productivity and facilitate new forms of scholarship. For more information about JSTOR, please contact support@jstor.org.

Your use of the JSTOR archive indicates your acceptance of the Terms \& Conditions of Use, available at https://about.jstor.org/terms

Linguistic Society of America is collaborating with JSTOR to digitize, preserve and extend access to Language 


\section{There is no third face of agreement}

\section{AleX Alsina \\ BoBAN ARSENIJEVIĆ \\ Universitat Pompeu Fabra \\ Universitat Pompeu Fabra}

The main claim of Alsina \& Arsenijević 2012a, henceforth A\&A, can be stated as in 1 .

(1) There is no evidence for the idea that there are three potentially distinct sets of features needed for accounting for agreement facts-two syntactic sets and one semantic set.

The kind of argument that would show this claim to be false or incorrect is one that presents a fact, or a set of facts, that can only be explained by positing two syntactic sets of agreement features, in addition to the corresponding semantic information, that is, that requires the $2 \mathrm{SAH}$ (the dual syntactic agreement hypothesis). None of the arguments in Wechlser \& Zlatic 2012, henceforth W\&Z'12, is of this kind. The arguments in W\&Z' 12 are mostly about possible problems that the analysis in A\&A might face when applied to constructions not discussed in A\&A.

A\&A focuses on hybrid nouns in Serbo-Croatian (S-C), since such nouns have been the main source of argumentation for the 2SAH in Wechsler \& Zlatic 2000 (W\&Z) and related work, and states generalizations within the 1SAH that account for the agreement facts involving such nouns. The argument in W\&Z'12 based on the data in their examples 2-3 and 5 simply indicates that syntactic gender has a default association with semantic gender, in which masculine corresponds to male and feminine to female. ${ }^{1}$ The argument illustrated by example 4 in W\&Z' 12 shows that syntactic number, like semantic gender, has a default semantic correlate, by which plural signals more than one entity, and that this semantic value emerges in certain constructions, such as the appositive construction in the example. ${ }^{2}$ If singular agreement is shown to be the default choice for finite verb agreement, as argued in W\&Z'12 on the basis of subjectless sentences and clausal subjects, all we need to do is to rephrase the statement about agreement in A\&A's 4 (p. 373) so that it reads: 'A plural verb form is required if the subject is plural, either semantically or syntactically; otherwise, a singular form is used'. When the syntactic head triggering agreement is of a category that does not carry the features involved in agreement, such as a clause, an infinitive, or an adverb (see W\&Z'12 exx. 6 and 8), singular agreement is predicted. ${ }^{3}$ As can easily be seen, all of these observations are not arguments for the $2 \mathrm{SAH}$ and are perfectly compatible with a theory that assumes the 1SAH.

The one instance in which the $2 \mathrm{SAH}$ seems to allow for a simpler statement than the 1SAH concerns personal pronouns. In W\&Z, personal pronouns are said to agree with their antecedents either in index features or in semantic features. In the proposal in A\&A, pronouns agree with their antecedents either syntactically or semantically, with syntactic agreement restricted to nominative case forms. The statement in W\&Z avoids this restriction, but it hinges on the homophony of all neuter plural forms of pronouns

\footnotetext{
${ }^{1}$ However, $5 \mathrm{~b}$ in W\&Z' 12 is judged in the range between highly degraded and fully ungrammatical by a sample of twenty speakers.

${ }^{2}$ Singular agreement is only possible in a nonrestrictive, appositive use of the adjective, as in example 4 in W\&Z'12, while the attributive prenominal use requires plural agreement.

${ }^{3}$ One should note that the quantifier mnogo in example 8 in W\&Z' 12 syntactically acts as the head of the phrase, in which the noun along with its features is embedded.
} 
with some other form: the nominative with the nominative feminine singular, and the remaining forms with the masculine/feminine plural form of the same case value. The price for dispensing with that restriction is (a) the massive complication that the $2 \mathrm{SAH}$ represents and (b) the stipulation that pronouns agree in index features, and not in concord features, with their triggers. And no empirical gain follows from this. In addition, restrictions relating case form to the choice of semantic or syntactic agreement are needed anyway, because relative pronouns allow semantic agreement only in certain case forms, as shown in W\&Z (p. 819) (see Alsina \& Arsenijević 2012b for an account).

W\&Z' 12 defends the neuter plural analysis of certain elements such as the pronoun ona agreeing with deca-type nouns by referring to Corbett (1983), rather than presenting the particular arguments. But A\&A already explicitly takes care of these arguments, showing that they either are fully compatible with the feminine singular analysis of those elements or are based on incomplete empirical generalizations (as in the case of coordination) and that additional data support the latter analysis.

In short, W\&Z'12 has an opportunity to make a case against the claim in 1, but, instead of doing so, discusses facts and issues that are irrelevant to that claim. By not presenting a single argument against that claim, W\&Z' 12 provides clear confirmation that the claim is correct.

\section{REFERENCES}

Alsina, Alex, and Boban ArseniJević. 2012a. The two faces of agreement. Language 88.369-79.

Alsina, Alex, and Boban ArSENIJEvić. 2012b. Hierarchies and competing generalizations in Serbo-Croatian hybrid agreement. Paper to be presented at the 17th International Lexical Functional Grammar Conference (LFG2012), Udayana University, Bali.

Corbett, Greville G. 1983. Hierarchies, targets, and controllers: Agreement patterns in Slavic. London: Croom Helm.

WeChSLER, STEPHEN, and LARISA Zlatić. 2000. A theory of agreement and its application to Serbo-Croatian. Language 76.799-832.

WeCHSLER, STEPHEN, and LARISA ZLATIĆ. 2012. The wrong two faces. Language 88.380-87.

Department of Translation and Language Sciences

[Received 30 April 2012;

Universitat Pompeu Fabra accepted 30 April 2012]

08018 Barcelona, Catalonia

[alex.alsina@upf.edu]

[b.arsenijevic@gmail.com] 